\title{
INDÍCIOS DE AUTORIA NA PRODUÇÃO DE RESENHAS DE ESTUDANTES DE ENSINO MÉDIO
}

\section{TRACES OF AUTHORSHIP IN SCHOOL REVIEWS BY HIGH SCHOOL STUDENTS}

\author{
Maria Marta Furlanetto* \\ Vinicius Valença Ribeiro**
}

\begin{abstract}
RESUMO
Este artigo apresenta uma análise dos indícios de autoria em três resenhas produzidas por alunos do segundo e do terceiro ano do Ensino Médio do Instituto Federal de Sergipe. Os pressupostos teóricos envolvem a perspectiva sociointeracionista do Círculo de Bakhtin e as orientações sugeridas por Possenti (2009a, 2009b, 2013). A teoria sociointeracionista norteia o planejamento para o trabalho com gêneros, autoria e estilo; as concepções de Possenti são mais específicas para o trabalho pedagógico com os indícios de autoria a partir da produção textual dos alunos, na qual se verifica o nível de controle dos recursos linguísticos. $\mathrm{Na}$ análise, avaliam-se as associações com elementos da cultura assim como as ocorrências de possíveis decisões enunciativas dos produtores, envolvendo tanto as escolhas vocabulares quanto a variação dos aspectos formais dos textos. Procura-se também relacionar as resenhas escolares a um lugar de enunciação. Esses aspectos mostram-se pertinentes para mapear os indícios de autoria nas resenhas analisadas.
\end{abstract}

Palavras-chave: gênero; autoria; resenha.

\section{ABSTRACT}

This article provides an analysis about traces of authorship in three school reviews produced by high school students attending second and third grades at Sergipe Federal Institute. The theoretical basis involves socio-interactionist perspective in Bakhtin Circle and guidelines suggested by Possenti (2009a, 2009b, 2013). The socio-interactionist theory guides the school planning concerning the class work with genres, authorship and style; Possenti's conceptions are more specific in regard to the pedagogical work about the traces of authorship in the students' writing production, where the control of linguistic resources is examined. In the analysis, it is examined the association with cultural elements as well as the occurrence of possible enunciative decisions made by producers, involving vocabulary choices and variation of the formal aspects in the texts. It is also attempted to relate the school reviews to a locus of enunciation. These features have proved relevant to observe the traces of authorship in the school reviews.

Keywords: genre; authorship; review.

\footnotetext{
* Universidade do Sul de Santa Catarina, Tubarão (SC), Brasil. mmarta@intercorp.com.br

** Instituto Federal de Educação, Ciência e Tecnologia de Sergipe, Aracajú (SE), Brasil. vinimacedo@ uol.com.br
} 
"não é tão ruim descobrir que o pensamento humano não produz muitas coisas boas quando só 'ocorre' isoladamente."

(Anthony Wall)

\section{INTRODUÇÃO}

Este trabalho está centrado no processo de autoria, mais especificamente admitindo-se a possibilidade de acompanhar sistematicamente o desenvolvimento da autoria em ambiente de ensino e aprendizagem; para seu desdobramento nos baseamos, em sua maior parte, na teoria sociointeracionista do Círculo de Bakhtin, seguindo os princípios de Bakhtin quanto a esse tema. A tecedura também procura instaurar e compreender, na produção de estudantes de Ensino Médio, indícios de autoria, seguindo a proposta de Possenti (2009a, 2009b, 2013). Três resenhas são analisadas para apontar os indícios e como eles variam de uma produção a outra.

Essa produção, em função de planejamento feito pelo primeiro autor para a segunda e a terceira série do Ensino Médio, foi elaborada em situação de sala de aula regular, mas já tendo em vista sua publicação em revista impressa criada e editada pelo próprio professor: Entretemas. Além de resenhas, outros gêneros e temas desfilam na revista: entrevistas, artigos de opinião, páginas literárias, cuja circulação se dá predominantemente no Instituto Federal de Sergipe, onde leciona o professor, mas há eventual distribuição (gratuita) da revista em outras escolas. O que não há, ainda, é muito controle sobre sua circulação e efetiva leitura. A revista representa um meio imediato de fazer circular a produção dos estudantes do Instituto. Contribui para isso, além da versão impressa, uma versão online em construção em < http://revistaifs.pe.hu/>.

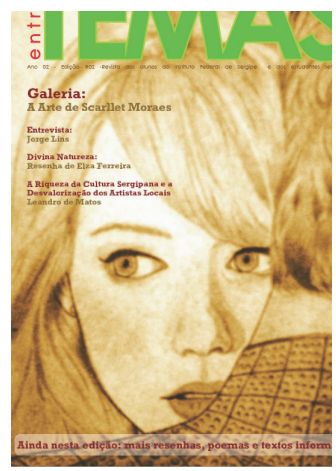

Figura 1 - Capa de uma edição de Entretemas

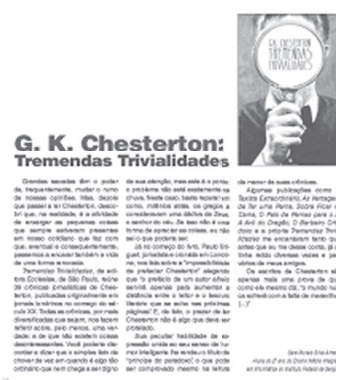

Figura 2 - Uma resenha'

\footnotetext{
1 A imagem é apenas ilustrativa. A resenha em questão é analisada adiante.
} 


\section{UM TRABALHO COM GÊNEROS}

Em seu trabalho com Língua Portuguesa no Instituto Federal de Sergipe, o professor coautor do presente artigo assume a perspectiva sociointeracionista no estudo da linguagem e da língua portuguesa. Empenha-se, pois, em fazer presente a voz dos alunos, além de investigar e valorizar os saberes adquiridos ao longo da vida e fora da escola. Com essa visão, dá-se também o trabalho com gêneros em sala de aula (prática prevista para todo o Ensino Médio).

Para todo novo gênero estudado, é proposta, primeiramente, a solução de um problema: os alunos são estimulados a responder ao questionamento: o que deve ter/ como deve ser um certo texto que vise atingir um objetivo tal? O outro passo é observar, através da leitura de gêneros diferentes, quais exemplares pretendem cumprir o objetivo discutido. Depois da primeira leitura, das discussões, e estando os estudantes mais ou menos cientes do gênero estudado, o passo seguinte é uma segunda leitura, apenas de exemplares do gênero em pauta. $\mathrm{O}$ intuito é identificar os traços comuns em termos de enunciados; de tipicidade enunciativa. Na medida do possível, levam-se à sala de aula os gêneros em seu próprio suporte, principalmente jornais e revistas. Esse é o traçado das aulas de leitura.

$\mathrm{Na}$ etapa de escritura, os alunos são orientados a produzir apenas um exemplar genérico, pois esse texto deve ser refeito algumas vezes, se necessário for, com um acompanhamento individualizado, entre professor e aluno. No caso da resenha, os alunos são estimulados a produzir textos sobre os livros, filmes, ou álbuns musicais de sua preferência. Isso lhes dá uma oportunidade de expressar opiniões e de compartilhar interesses sobre o que de fato vivenciam por sua própria iniciativa. Uma prática do professor é a de despertar os alunos para a pesquisa sobre o elemento resenhado. Pretende-se que eles criem associações entre seus saberes anteriores, as novas informações adquiridas sobre o tema tratado em suas resenhas e outros discursos disseminados no meio social. A publicação possível em Entretemas permite aos alunos vivenciarem o processo de escritura a partir de uma outra perspectiva sobre o propósito dos textos, pois sabem que o professor não é o fim do processo, mas, sim, os leitores, que talvez sequer conheçam (cf. a perspectiva de Barthes apresentada na próxima seção).

\section{O PROCESSO DE AUTORIA - PERSPECTIVAS}

Revisitando Foucault (1969/1997) com respeito à autoria, constatamos que a função-autor, como papel específico da subjetividade, resulta de um processo dialético 
entre a concepção de autoria como função de um sujeito racional e o apagamento do autor, processo conhecido desde que Barthes (1984/2004), em artigo de 1968², anunciou sua morte, e posteriormente Derrida (1990/1991), que promoveu sua desconstrução.

Se bem que voltado para o mundo da literatura, Barthes nos traz lições que podemos estender para outras dimensões da vida em sociedade. Ele diz, no início de seu texto, que "a escritura é a destruição de toda voz, de toda origem." (1984/2004, p. 57). Embora pareça escandalosa, essa afirmação faz sentido, visto que algo contado, que não seja uma ação dirigida diretamente para o real, acaba por produzir um desligamento da origem, da voz, do autor, que perde sua identidade. A escritura começa a produzir efeito, o autor se perde no tempo. Na perspectiva de Barthes, o autor é uma personagem moderna, que não existia como a entendemos um fenômeno que surge com o fim da Idade Média e certos movimentos filosóficos (empirismo inglês, racionalismo francês), que acabaram descobrindo "o prestígio do indivíduo ou, como se diz mais nobremente, a 'pessoa humana'." (BARTHES, 1984/2004, p. 58). Mais especificamente, com a ideologia capitalista, a pessoa do autor se tornou uma figura importante, com "direitos de autor" no mercado. E os próprios autores, em geral, são muito ciosos "por juntar, graças ao seu diário íntimo, a pessoa e a obra" (1984/2004, p. 58).

Quando se exerce a autoria ou se desenvolve seu aprendizado, fica razoavelmente compreensível por que Barthes trabalhou essa perspectiva: não seria a linguagem que fala em nós, que nos atravessa, em vez de nossos pensamentos individuais e criatividade? Barthes verificou que a própria Linguística, em seu tempo, abrindo-se para a compreensão dos processos enunciativos, produziu, para a destituição do Autor (com maiúscula), um instrumento analítico de peso, mostrando que

a enunciação em seu todo é um processo vazio que funciona perfeitamente sem que seja necessário preenchê-lo com a pessoa dos interlocutores: linguisticamente, o autor nunca é mais do que aquele que escreve, assim como "eu" outra coisa não é senão aquele que diz "eu": a linguagem conhece um "sujeito", não uma "pessoa", e esse sujeito, vazio fora da enunciação que o define, basta para "sustentar" a linguagem, isto é, para exauri-la. (BARTHES, $1984 / 2004$, p. 60)

Assim, Barthes julga que aquele que escreve "nasce ao mesmo tempo que seu texto" (1984/2004, p. 61), ele não preexiste ao texto: "outro tempo não há senão o da enunciação, e todo texto é escrito eternamente aqui e agora." (1984/2004, p.

2 O rumor da língua é uma coletânea que reúne escritos de Barthes produzidos entre 1964 e 1980. 
61, grifo do autor). E o que é importante para nós, hoje: o texto é "um espaço de dimensões múltiplas, onde se casam e se contestam escrituras variadas, das quais nenhuma é original: o texto é um tecido de citações, oriundas dos mil focos da cultura." (1984/2004, p. 62). Nesse sentido, o que fazemos como produtores é buscar ou imitar um gesto anterior.

Mas há um aspecto importante nisso tudo, que corresponde ao que podemos chamar autoria agora: o poder do escritor "está em mesclar as escrituras, em fazêlas contrariar-se umas pelas outras, de modo que nunca se apoie em apenas uma delas" (BARTHES (1984/2004, p. 62). É também por essa perspectiva que é tarefa inútil tentar "decifrar" um texto, como se pudéssemos chegar lucidamente ao autor em suas pretensões como escritor. A escritura abre para sentidos, para efeitos que possamos nela suspeitar. E Barthes, ao final desse pequeno texto pesado de consequências, ainda diz que a multiplicidade reinante no texto se reúne não no autor, mas no leitor: a unidade do texto estaria no seu destino, o leitor, que é "esse alguém que mantém reunidos em um mesmo campo todos os traços de que é constituído o escrito" (1984/2004, p. 64). O leitor tem o privilégio de dispor de um texto aparentemente fechado em sua organização, e ao mesmo tempo aberto para suas viagens, para sua inspiração e uso.

E que fez Derrida? Num texto intitulado Assinatura acontecimento contexto, tentou desconstruir noções vinculadas à escrita, entre as quais intenção e consciência. Para ele, a ausência é uma especificidade da escrita, que ele remete imediatamente ao destinatário (distanciamento). Para funcionar, a escrita precisa de instrumentos que levem à legibilidade do texto, o que implica a iterabilidade/repetição. Mas aquele que escreve também se apaga, e o importante no processo é que resta uma marca (cicatriz), que resiste ao nosso desaparecimento.

Assim, se tomarmos o querer-dizer autoral - a direcionalidade em um projeto discursivo -, a intenção específica do projeto vai se desvanecer. Rompe-se também o contexto imediato da produção, de modo que a escritura fica à deriva. Trata-se novamente, então, de uma morte, de ausência. O que resta do autor? Sua assinatura e um nome, que podem se repetir em cada cópia. E persiste o leitor e as possibilidades infindáveis de leitura.

Foucault (1969/1997), por sua vez, em O que é um autor?, procurava especificidades relativas ao modo de ser do autor, que seria anterior e exterior ao texto. Há um jogo entre fechamento e abertura, forças antagônicas entre o que seria regularidade e risco de transgressão na escritura: "a escrita desdobra-se como um jogo que vai infalivelmente para além das suas regras, desse modo as extravasando", e nesse movimento "o sujeito de escrita está sempre a desaparecer" (1969/1997, p. 
35). Indo na mesma direção de Derrida, Foucault destaca que "a marca do escritor não é mais do que a singularidade da sua ausência" (1969/1997, p. 36). Contudo, preocupa-o especificamente o modo de existência do autor, assumindo que não o reduz meramente a uma função, tal como estabelecido na denominação função-autor. $\mathrm{O}$ nome de autor é uma marca com estatuto cultural que cria um imaginário, sem remeter, entretanto, diretamente a uma figura empírica. Outro aspecto importante (e restritivo) desse tratamento é que essa função só diz respeito a alguns discursos no interior da sociedade, cujo "modo de existência, de circulação e de funcionamento" (1969/1997, p. 46) teriam interesse social: discursos de autoridade, discursos que fundam discursividades.

Tais perspectivas, de caráter filosófico, não nos levam diretamente às questões pedagógicas de produção discursiva, mas fazem com que nos aproximemos dos conflitos relativamente à produção autoral, restando nossa própria possibilidade de compor um projeto com noções aplicáveis aos objetivos de desenvolvimento da autoria em qualquer materialidade de linguagem e com sujeitos aprendizes.

Entendemos, portanto, que não se trata de autoria no sentido das perspectivas apreciadas acima, que se referem à produção de uma obra (literária, filosófica, religiosa ${ }^{3}$ ) ou à produção de uma discursividade (que se expandirá pela retomada incessante de "comentadores" que se inspirarão nela), da qual o nome de autor é parte da legitimidade jurídica da obra. Ainda assim, o autor (autor-criador), nesses casos, não aparece como uma entidade singular, como sujeito pragmático, entidade biológica, mesmo havendo uma conexão entre este e aquele que mostra uma produção, algo concluído. Na ótica bakhtiniana, o autor está fixado no texto estruturalmente, de modo invisível (CLARK; HOLQUIST, 1984/1998, p. 112). Nesse sentido é que nossa apreciação de um texto se restringe ao texto, é o que vamos interpretar - e não à vida familiar ou amorosa desse autor. Em todas as perspectivas isso parece consensual. O autor se define como uma posição de caráter discursivo.

Possenti (2013, p. 240), ao fazer a comparação com a perspectiva de Foucault e o tratamento de estudiosos da autoria no Brasil, especialmente aqueles do campo da Análise de Discurso, diz que, para estes, "são autores os que escrevem um texto adequado." - tratando-se, especificamente, da relação entre sujeito e texto, e não entre autor e obra. É desse modo que ele chega à expressão "indícios de autoria", ou seja, a uma potencialidade que diz respeito, em síntese, à ideia de controle do que um sujeito propõe quando escreve, controle das possibilidades de deriva que

3 Ainda assim, nem todos os autores têm a mesma envergadura. 
leva a alguma aproximação do modo como autores reconhecidos trabalham - o que nem sempre sucede no contexto escolar, exatamente onde gostaríamos de detectar tais traços, para estimular a produção. Seria possível, então, imaginar um vetor, uma barra em que um botão desliza de zero a dez, por exemplo, mostrando vários níveis de autoria, desde mera reprodução automática até o resultado de algo bem projetado e desenvolvido, com efeito de autoria. Na posição de pesquisadores, estritamente falando, temos o status de autores, juridicamente falando (incluindo a responsabilidade), mas ainda assim não seríamos Autores - no sentido mais restrito de Foucault.

Importa, contudo, o reconhecimento de que os alunos possam escrever paulatinamente textos melhores, contando com atividades adequadas de expressão, sem que se tornem escritores com o nível de autoria tal como explicitado por Foucault. Em qualquer profissão, afinal, há oportunidade, quando não exigência, de que alguma coisa se escreva. E então cabe às instituições educacionais prover os meios para isso.

Nossa opção, aqui, é explorar algumas possibilidades oferecidas pelo sociointeracionismo ou abordagem histórico-social do Círculo de Bakhtin, especialmente do próprio Bakhtin, que tem permitido um olhar aberto para os interesses da Linguística Aplicada. Aliás, mostramos também que a perspectiva de Bakhtin sobre autoria diverge daquelas comentadas antes. A autoria tem um espectro dialógico que funda toda a existência. Em "O problema do texto na linguística, na filologia e em outras ciências humanas", ele destaca o caráter heteroglóssico da linguagem: falares, registros, vozes sociais que se emaranham e trazem tons específicos e índices sociais de valor que impregnam as mentalidades. E assevera (BAKHTIN, 1979/2010, p. 308): "Todo texto tem um sujeito, um autor (o falante, ou quem escreve).". Há tipos, modalidades e formas de autoria. "A forma de autoria depende do gênero do enunciado. Por sua vez, o gênero é determinado pelo objeto, pelo fim e pela situação do enunciado." (1979/2010, p. 389). Isso depende também da posição ocupada por quem se enuncia e para quem se enuncia. Assim sendo, "a mesma pessoa real pode manifestar-se em diversas formas autorais" (1979/2010, p. 390).

Clark e Holquist (1984/1998, p. 37) comentam:

O modo como os valores assumem a forma de expressão, introduzindo diferenças em um complexo elástico mais do que em uma unidade estática, é o que Bakhtin entende por atividade autoral. Destarte, todos nós que efetuamos declarações compreendidas como tais, quer faladas quer escritas, somos autores. Nós operamos a partir de um ponto de vista, e moldamos valores como formas. 
Vamos articular essa ótica com a realidade dos gêneros. A constituição sóciohistórica dos gêneros, em sua vinculação com a noção discursiva de enunciado, na teoria de Bakhtin (1979/2010), foi um passo importante para a compreensão do papel e funcionamento dos gêneros nas sociedades. Considerando que todas as formas de linguagem são submetidas às forças centrípetas (de regularização, levando à estabilidade) e centrífugas (de dispersão, levando à variação), temos de observar os gêneros como apenas relativamente estáveis, e não como modelos rígidos para a produção de textos - a sociedade muda e a língua manifesta isso caracteristicamente, deixando marcas: "O destino da palavra é o da sociedade que fala." (BAKHTIN/VOLOSHINOV, 1929/1986, p. 194). Entre os caminhos para estudar a evolução dialética da palavra encontramos o da evolução da própria língua "como material ideológico, como meio onde se reflete ideologicamente a existência [...]" (1929/1986, p. 194, grifo do autor).

Apesar da heterogeneidade e da plasticidade dos gêneros, um elemento que lhes garante identidade é o pertencimento do enunciado a uma esfera de comunicação, visto que cada esfera de produção tende a formar e especializar seus próprios gêneros, indicando por isso mesmo que há uma organização hierarquizada das relações sociais. Tratar de autoria, neste contexto, pressupõe textos conformados a gêneros, e neste trabalho um gênero que, em nível especializado, corresponde a um trabalho crítico de obra literária: resenha ou recensão. O que está em questão é o aprendizado desse gênero, que implica seguir algumas normas consoante o que se entende, contemporaneamente, como resenha na esfera das Letras.

As resenhas aqui analisadas têm em seus aprendizes autores o que Bakhtin chama "segundo sujeito", que "cria um texto emoldurador (que comenta, avalia, objeta, etc.)." (1979/2010, p. 309). Nessa criação haverá "o sistema da linguagem", tudo o que representa repetição, o que já está disponível; e algo que será a construção singular (mais ou menos marcada) de um sujeito, imprimindo sentido (como explicitamos na próxima seção). Assim, ao sistema envolvido na construção do texto podemos também denominar estrutura, e ao que é historicamente mobilizado, acontecimento, que implica relações dialógicas. Só então podemos falar em autoria.

\section{INDÍCIOS DE AUTORIA}

Para trabalhar os indícios de autoria do ponto de vista pedagógico, três textos de Possenti são relevantes: "Enunciação, autoria e estilo" (2009a), "Indícios de autoria" (2009b) e "Notas sobre a questão da autoria" (2013). Vamos admitir, 
inicialmente, seguindo Bakhtin (1979/2010), um marco para o planejamento do trabalho com gêneros: toda produção supõe a formulação de um projeto discursivo, que pode ser assim explicado: o projeto discursivo implica "a orientação para o outro tanto a montante (a fonte ou fontes, os autores) como a jusante (o destinatário) - respectivamente: a busca e seleção de materialidades ou recursos para a construção do texto, e a consideração dos leitores (reais ou apenas potenciais)." (FURLANETTO, 2014, p. 68-69). Com efeito: a interpretação não é privilégio do leitor; ela ocorre "como correlacionamento com outros textos e reapreciação em um novo contexto (no meu, no atual, no futuro)." (BAKHTIN, 1979/2010, p. 401). A interpretação é um movimento dialógico. E ler e escrever são práticas com implicação mútua. Escutando ou lendo, fazemos conexão com a exterioridade, com o mundo real, vivido; trazemos para nosso círculo o que é produzido nos espaços de alteridade, e tentamos controlar a dispersão consequente para obter efeito de fechamento.

Um projeto de dizer, mesmo que difuso, não formal, representa uma direção, que pode ser fornecida por um docente, em situação de aprendizagem, e tem duas dimensões: o da repetição ou iteração, que corresponde à busca, em uma memória, de algo já existente, já enunciado e disponível, a começar pela própria língua que será mobilizada, e em seguida por materiais disponibilizados e conhecidos (o texto vive se tem contato com outros textos, e, por essa via, com seus autores); e o da alteração, que corresponde ao esforço autoral de produzir algo distinto, ou seja, um efeito subjetivo. O trabalho autoral, efetivamente, busca o efeito de que algo, em certas condições, foi apresentado como uma peça unitária que produza sentido para outrem. Seguindo Bakhtin (1979/2010, p. 381), um enunciado produzido é resposta, num conjunto de enunciados que se encadeiam indefinidamente, fazendo sentido: "Chamo sentidos às respostas a perguntas." Ao fazê-lo, encontramos também, como expressa Bakhtin (1979/2010, p. 391), algo essencial: "o mundo dos tons e matizes pessoais, mas não em relação aos objetos (fenômenos, conceitos), e sim ao mundo das personalidades dos outros." O tom opera "pela relação do falante com a pessoa do interlocutor" (1979/2010, p. 391). Outra forma de dizer isso é que pegamos "conteúdo velho (conhecido)" como forma, e a forma "serve de ponte necessária para um conteúdo novo, ainda desconhecido" (BAKHTIN, 1979/2010, p. 405).

Ao reinterpretar a noção de estilo, agregada inevitavelmente à autoria, Possenti, deixando de lado a perspectiva clássica da retórica e da oratória, e igualmente a romântica, como expressão de uma subjetividade psicológica, radical, propõe entendê-la como "um modo de organizar uma sequência (de qualquer extensão), tendo como fundamental a relação entre essa organização e determinado efeito de 
sentido" (POSSENTI, 2009a, p. 93). Se escolhas precisam ser feitas e os recursos disponíveis para a expressão são múltiplos (se não fossem seria relativamente fácil realizar opções), é possível concluir que elas surgem exatamente como "efeito da multiplicidade dos recursos, que competem entre si a todo instante" (2009a, p. 93) - sem esquecer, no entanto, que tais escolhas não são mera questão de livre arbítrio, visto que o efeito associado é de "uma inscrição (seja genérica, seja social, seja discursiva)" (2009a, p. 93-94). Assim, ao lado do que o autor apresenta como indícios de autoria, haveria "traços de estilo" a caracterizar uma produção, com mais ou menos destaque.

Ao apresentar o que propõe como indícios de autoria, Possenti (2009b, p. 110) deixa expresso que se trata de como dizer e não diretamente de o que dizer (o que tradicionalmente chamamos de conteúdo). Ele destaca: "As verdadeiras marcas de autoria são da ordem do discurso, não do texto on da gramática" (grifos do autor). Relembrando Bakhtin/Voloshinov, diremos que se trata de uma questão de sentido, não de significado, que apresenta apenas potencialidade (1929/1986, p.131).

$\mathrm{Na}$ qualidade de professor que atuou, na Rússia, no ensino correspondente ao nosso médio, Bakhtin (1940-1945/2013) tratou de efeitos estilísticos a partir de construções gramaticais, elaborando um procedimento metodológico para conduzir os estudantes à percepção de efeitos que poderiam obter em seus textos trabalhando possibilidades de escolha que a língua permitia - num sentido mais formal, oferecendo paráfrases, mas atentando para as implicações semânticas e estilísticas. Bakhtin utilizou recortes de obras de escritores russos para trabalhar, especificamente, a construção conhecida como "período composto por subordinação sem conjunção" (uma forma de elipse), comparando-a em seus efeitos com versões em que as conjunções apareceriam. Apontava, na ocasião, a dramaticidade do efeito na medida da leitura oral modulada do romance, eventualmente acompanhada de gestos. Podemos dizer que o efeito produzido era de um uso mais elegante, mais sensível da língua. Uma abordagem estilística se destaca

quando o falante ou o escritor tem a possibilidade de escolher entre duas ou mais formas sintáticas igualmente corretas do ponto de vista gramatical. Nesses casos, a escolha é determinada não pela gramática, mas por considerações puramente estilísticas, isto é, pela eficácia representacional e expressiva dessas formas. (BAKHTIN, 1940-1945/2013, p. 25)

As línguas oferecem inúmeras possibilidades desse tipo: reduções, inversões, transformações; adequadamente observadas e construídas, abrem caminho para uma linguagem própria. Bakhtin expôs uma lição a partir desta frase de Púchkin: 
a) Triste estou: o amigo comigo não está.

Paralelizou-a com estas outras, mostrando as diferenças de expressividade, de dramaticidade.

b) Triste estou, porque o amigo comigo não está.

c) Estou triste, porque o amigo não está comigo.

d) Estou triste, uma vez que o amigo não está comigo.

Da comparação dessas versões já se pode tirar uma lição importante: a economia/concisão possibilitada pelo uso dos dois pontos, e isto não apenas na expressão de caráter literário, embora Bakhtin alerte sobre "a importância da subordinação com conjunções na linguagem prática e científica" (1940-1945/2013, p. 39). Na língua portuguesa, pelo menos, a concisão pode ser obtida com a economia de conjunções e outros juntores:

1. Vale destacar aqui: as respostas estão corretas.

1a. Vale destacar aqui que as respostas estão corretas.

2. Esta prática não cabe ao professor ou ao aluno, visto que seus interesses são outros.

2a. Esta prática não cabe ao professor ou ao aluno: seus interesses são outros.

2b. Esta prática não cabe ao professor ou ao aluno: eles têm outros interesses.

Retornemos aos indícios apresentados por Possenti (2009b). Em seu texto, ele explora três indícios relativos a atitudes na construção de um texto: dar voz a outros enunciadores, manter distância em relação ao próprio texto, evitar a mesmice. De certa forma, dar voz a outros enunciadores - essencial porque corresponde à busca de saberes necessários como ponto de partida para uma produção discursiva - implica, na prática, se o processo não for automático (copiar-colar), tomar posição relativamente às materialidades transportadas, estabelecendo, com menos ou mais adequação, uma tecedura em que as vozes (com seus saberes) possam ser distinguidas e ao mesmo tempo avaliadas em relação ao que trazem.

Assim, tomar posição é um dos comportamentos linguísticos indiciários de autoria, e é uma modalidade do manter distância do próprio texto, que exige apreciação. Se dar voz é aproximar-se de outrem (fazendo um retorno ao passado, ao pequeno tempo ou ao grande tempo (BAKHTIN, 1979/2010, p. 409), buscando entendê-lo, tomar posição significa, nessa conversa, tomá-lo como argumento, no todo ou parcialmente, ou 
contradizê-lo. Já se trata de um passo na interpretação. Bakhtin (1979/2010, p. 381) expressa isso remetendo à necessidade de compreender uma obra aproximando-se de seu autor e, em seguida, estabelecer uma distância temporal e cultural, trazendo-o para novo tempo e espaço (reapreciação, posicionamento). Ou seja, cabe afastarse do outro olhar para assumir o próprio ponto de vista. Na resenha, isso emerge principalmente do julgamento acerca do que é resenhado. O julgamento consiste em um dos elementos de maior estabilidade enunciativa desse gênero. Uma vez que reivindica a avaliação e, portanto, a tomada de posição, a resenha mostra que é um gênero com potencial de abertura a traços autorais.

$\mathrm{Na}$ resenha, o ato de julgar é fenômeno que encerra, simultaneamente, ancoragens e périplos. No primeiro caso, é centrípeto, porque, de uma perspectiva discursiva, é ato de linguagem regular, comum, no discurso do jornalismo. Além disso, de uma perspectiva genérica, o julgamento é um dos traços que força a estabilidade de certos textos jornalísticos, principalmente artigos de opinião, editorais e resenhas. No segundo caso, por outro lado, julgar é fenômeno centrífugo, pois instaura o risco, impelindo o resenhista a colher soluções em outros espaços discursivos além do topos jornalístico. Portanto, a despeito da força tópica implicada pelo discurso do jornalismo cultural, no caso de resenhas admite-se a ocorrência de deslizamentos, deslocamentos e atravessamentos nesse discurso, o que abre alguns caminhos para a autoria ou seus indícios. O resultado histórico desse conjunto é a própria transformação paulatina - genérica e/ou discursiva. Sobre isso, Furlanetto $(2015$, p. 600) deixa entrever a possibilidade de "como espaços que guardam mais homogeneidade (considerando regras mais exigentes) acabam negociando, no curso do tempo, a incorporação de elementos 'de fora' e sua transformação gradativa".

Essa propriedade é válida não só para as resenhas produzidas por críticos profissionais, mas também para a resenha escolar, que se apresenta como um exercício, válido para os pares na medida de sua circulação e leitura, mas não como uma produção com legitimidade profissional, que induziria a falar em autoria no sentido estrito. No entanto, a abertura do gênero a um trabalho de autor, especialmente no segundo caso, não é determinante para que surjam inexoravelmente indícios sempre marcantes desse trabalho. Por isso, os textos escolares desse gênero nos chegam sempre com muita variação entre os indícios de autoria. Há sujeitos que se mostram mais e outros menos. Isso pode ser visto também entre as três resenhas analisadas neste artigo. Os três textos apresentam bons indícios, mas entre eles, há variação visível de uma presença identitária.

Tomar posição (de avaliação), para nós, aparece aqui valendo também como retorno às próprias palavras, aos achados: explicando atitudes, retomando, repetindo, 
glosando (isto é, ou seja, melhor dizendo, como diria...). É o que Authier-Revuz (2008) tem chamado de estrato metaenunciativo, um acompanhamento normal do dizer que se desdobra, e que funciona como "uma restauração imaginária do controle sobre o dizer" (2008, p. 34).

Finalmente, evitar a mesmice diz respeito a não se restringir ao iterar, seja relativamente ao que dizem os outros, seja a manipulações linguísticas estereotipadas - clichês, formulações de senso comum. Retornando a Bakhtin sobre as possibilidades estilísticas das construções sintáticas, entre outras, vemos aí uma abertura para o exercício de busca, comparação e escolhas baseadas na abertura da língua para produzir efeitos variados e nos projetos de dizer esboçados.

Os textos de um número significativo de alunos são bem ajustados ao que eles compreendem como o gênero resenha. $\mathrm{O}$ ajustamento é possivelmente uma consequência da leitura e do estudo, em sala de aula, de resenhas que circulam no meio social em revistas ou jornais. Existe, então, uma inclinação dos alunos em tentar acomodar ao máximo os seus textos aos elementos mais estáveis do que perceberam nos equivalentes mais ritualizados do gênero. Entretanto, nas resenhas escolares surgem alguns enunciados que não estão entre os mais previstos nos textos produzidos por críticos profissionais.

Isso não significa, absolutamente, prejuízo à produção escolar. Primeiro porque nossa experiência mostra que o mesmo acontece com outros gêneros produzidos na escola. Supomos, então, que aquilo que não se prevê, por exemplo, em exemplares jornalísticos de um determinado gênero, pode ser parte de um processo de estabilização de enunciados próprios do equivalente genérico escolar. Em segundo lugar, não enxergamos um problema nisso porque não endossamos a ideia de características genéricas, que preconiza uma ilusória e total estabilidade do gênero produzido, esteado em um modelo idealizado. É mais adequada a ideia de regularidades, concepção que reconhece a estabilidade do gênero, mas também sua relatividade.

Mesmo que na escola sempre haja monitoramento da produção textual, não devemos confundir acompanhar e orientar com estabelecer e cobrar regras invioláveis. Em última análise, devemos observar e respeitar o lugar social de onde se enuncia. Estamos tratando de alunos que produzem textos na escola, ou pelo menos durante a vida escolar. Essa produção não escapa a uma série de constrições. Então, o que é atípico na resenha profissional, no texto do aluno pode ser o próprio indício de autoria porque o modo de dizer sinaliza a inscrição em um discurso e o pertencimento a um grupo, a um lugar de enunciação com inclinações particulares. 


\section{UM OLHAR ANALÍTICO}

O material selecionado para análise compõe-se de três resenhas de estudantes de Ensino Médio do Instituto Federal de Sergipe.

Resenha 1 - O conde de Monte Cristo, de Alexandre Dumas. [DUMAS, A. O Conde de Monte Cristo (Vol. I). Martin Claret, São Paulo, 2008.]

O livro O Conde de Monte Cristo, de Alexandre Dumas, conta a história de Edmond Dantès, um jovem marinheiro que acaba sendo preso, vítima de uma armação maquinada por Danglars, que não desejava que o jovem se tornasse capitão do navio Faraó. Mas quem executa a armação é Fernando, um jovem catalão que ama a mesma mulher que Dantès.

$\mathrm{N}$ a p r i s ã o, E d m o n d conhece o abade Faria, que era clérigo antes de ser preso. Ele é um homem que poderia ser chamado de enciclopédia viva, pois tem conhecimento em várias áreas da ciência, além de falar várias línguas. Faria ensina uma boa parte do que sabe ao jovem, tornando-se assim seu companheiro, instrutor e pai. Antes de ter uma morte horrível, causada por ataques de apoplexia, deixa, com Dantés, a localização do enorme tesouro perdido da família Spada, a qual serviu durante muito tempo. No decorrer da história, Dantès consegue fugir da cadeia, planejar e executar uma vingança.

Essa história foi dividida em três livros, dos quais estou lendo o primeiro e indico a todos, pois é uma trama muito bem orquestrada que estimula nossa inteligência, além de conter muitos fatos e personagens históricos, como Napoleão Bonaparte na sua fuga da ilha de Elba para recuperar o trono perdido. É algo que dá um tom maior de veracidade ao romance. Este livro, assim como vários outros de Alexandre Dumas, consegue prender a atenção do leitor e viciá-lo na história.

De maneira geral, o gênero resenha implica uma contextualização, descrição ou resumo, dependendo do tema (livro, filme etc.), e uma avaliação. Nessa resenha, os dois primeiros parágrafos são o resumo da história do livro: o Conde de Monte Cristo. O terceiro e último parágrafo traz uma avaliação e alguns comentários sobre a obra. Não é incomum que resenhas escolares sejam bem sistemáticas: o que é entendido como elementos regulares do gênero aparecem bem demarcados e separados em parágrafos. Há textos, por exemplo, em que no resumo categoricamente só se resume e em um outro bloco de texto categoricamente só se avalia. Nesse sentido, o texto sob análise é bem circunscrito ao gênero, mas em alguns momentos o resenhista escapa de ser tão conservador. Com isso em vista, começamos pelo segundo parágrafo, parte do resumo do livro:

$\mathrm{N}$ a p r i s ã o, E d m o n d conhece o abade Faria, que era clérigo antes de ser preso. Ele é um homem que poderia ser chamado de enciclopédia viva, pois tem conhecimento em várias áreas da ciência, além de falar várias línguas. Faria ensina uma boa parte do que sabe ao jovem, tornando-se assim seu companheiro, instrutor e pai. Antes de ter uma morte horrível, causada 
por ataques de apoplexia, deixa, com Dantès, a localização do enorme tesouro perdido da família Spada, a qual serviu durante muito tempo. No decorrer da história, Dantès consegue fugir da cadeia, planejar e executar uma vingança.

Temos uma posição avaliativa sobre um personagem do livro - [...] que poderia ser chamado de enciclopédia viva. A avaliação entrecruza o resumo. Logo, não se trata de resumir por resumir, no sentido de somente reproduzir elementos regulares de uma resenha, como o resumo. Ademais, justifica-se o julgamento com uma explicação - pois tem conbecimento em várias áreas da ciência, além de falar várias línguas. Ater-se ao detalhe, daí a explicação, faz-nos entender que isso é tido como algo importante para o produtor do texto, além de implicar atitude dialogal (tendo em mente o interlocutor). Explicar, mesmo concisamente, consiste, portanto, em uma decisão possível desse enunciante. A avaliação ainda não é do livro, mas de um personagem da narrativa, o que sugere uma preocupação em informar um pouco mais o leitor, saindo da síntese geral para o dado específico. A avaliação seguida de explicação se repete. Temos uma avaliação taxativa em - Antes de ter uma morte borrível - e uma explicação para o que é avaliado - causada por ataques de apoplexia [...].

Voltemos ao primeiro enunciado para observar um tipo de distanciamento com movimento de valoração - que poderia ser chamado de enciclopédia viva. $\mathrm{O}$ uso do futuro do pretérito no segmento suscita uma abertura a outra voz. Isso se aproxima da suposição de como os interlocutores do texto poderiam conceber o personagem avaliado - "que poderia" [...]. Ou seja, outras vozes poderiam também classificar o personagem dessa maneira, embora, em verdade, a classificação seja realizada pelo próprio enunciante da resenha. O interessante é observar o mecanismo de inclusão, que resulta de uma escolha linguística referente ao tempo verbal. Supondo que o verbo estivesse em um outro tempo, por exemplo, no presente do indicativo - pode - ocorreria uma fechamento para a alteridade. De qualquer forma, a escolha, aqui, não está atribuída a um ente autônomo diante da linguagem. Possenti (2009a, p. 93-94) explica que a escolha resulta de "[...] uma multiplicidade de alternativas decorrente de concepções de língua como objetos heterogêneos -, diante das quais escolher não é um ato de liberdade, mas o efeito de uma inscrição (seja genérica, seja social, seja discursiva)". Optar entre dois tempos verbais para provocar um efeito só é possível porque as alternativas são disponibilizadas pela linguagem. Por outro lado, esmerilhar um texto pressiona, de modo inequívoco, a escolher entre esses recursos não criados por um psicologismo absoluto, mas apenas disponíveis. É nesse movimento que se dá entre uma e outra escolha que está o indício de um trabalho autoral.

Vamos ao terceiro parágrafo: 
Essa história foi dividida em três livros, dos quais estou lendo o primeiro e indico a todos, pois é uma trama muito bem orquestrada que estimula nossa inteligência, além de conter muitos fatos e personagens históricos, como Napoleão Bonaparte na sua fuga da ilha de Elba para recuperar o trono perdido. É algo que dá um tom maior de veracidade ao romance. Este livro, assim como vários outros de Alexandre Dumas, consegue prender a atenção do leitor e viciá-lo na história.

Ressaltamos uma incidência de verbo flexionado em primeira pessoa do singular ${ }^{4}$. Em resenhas produzidas por críticos profissionais, é um traço mais atípico. Em nosso caso, ao longo da experiência, não tem sido raro encontrar essa forma em certos gêneros quando desenvolvidos por alunos, ainda que seus equivalentes mais institucionalizados tendam a subtraí-la. Tratando-se ainda de uma resenha parcial admissível na situação -, ocorre ser indispensável essa visada mais particular.

No que tange à resenha sobre $\mathrm{O}$ Conde de Monte Cristo, não é somente a ocorrência pura e simples da primeira pessoa do singular que indica um desempenho ${ }^{5}$ nos limites do gênero. É, também, como essa forma, a primeira pessoa do singular, incide e os efeitos que provoca. A ocorrência sinaliza um lugar discursivo escolar e/ou do alunato. Há um efeito de despojamento - em uma boa acepção, um traço de estilo. Está assumida a leitura ainda não finalizada do primeiro livro, mesmo com a resenha pronta e publicada - "estou lendo" o primeiro [...] -, e pressupõe-se uma necessidade, ou desejo, de aprender, que passa a incluir todo o grupo em que o enunciante se situa - [...] que estimula "nossa" inteligência.

A construção de uma autoridade crítico-enunciativa, que recomenda ou não um produto cultural, consiste em um dos elementos mais estabilizados em resenhas de outras esferas de produção. Diferentemente, no texto sobre O Conde de Monte Cristo, a carga de autoridade vem amainada. O julgamento e a indicação do livro estão presentes sem constituir uma autoridade pujante. Ao invés disso, há, mais claramente, uma abertura a uma espécie de intimidade estudantil - estou lendo o primeiro e indico a todos, pois é uma trama muito bem orquestrada que estimula nossa inteligência. Ou melhor, de compartilhamento do saber, levando-se em conta o endereçamento, a circulação, e o alcance da resenha. Seu suporte, a revista Entretemas, circula, especialmente, no Instituto Federal de Sergipe e é lida, sobretudo, por seus alunos.

No parágrafo sob análise, a avaliação não focaliza mais um detalhe do livro ou de uma personagem. Avalia a obra como um todo. Chamamos a atenção, porém, para a intercorrência do procedimento de explicar e justificar a avalição, como vimos no segundo parágrafo. $\mathrm{O}$ arranjo é um pouco diferente porque a explicação

4 De agora em diante, por uma questão de economia, apenas primeira pessoa do singular.

5 Aqui o termo 'desempenho' não é usado no sentindo chomskyano. 
é o próprio julgamento, que justifica a leitura do livro - pois é uma trama muito bem orquestrada que estimula nossa inteligência.

Além disso, observamos traços autorais na utilização de recursos vocabulares interessantes. As ocorrências da expressão bem orquestrada e do verbo estimular sugerem um cuidado com a composição dos enunciados. Cumpre-se um dos papéis do resenhista genérico, o da avaliação, porém, há o toque autoral, perceptível em torno da ampliação das possibilidades vocabulares. Não se enuncia apenas se o livro é bom ou ruim. Não se usam apenas adjetivos. A variação formal não se restringe à parcela avaliativa do texto e é verificada ao longo de toda a resenha. Apenas alguns exemplos: armação maquinada, jovem catalão, tom maior de veracidade, viciá-lo na bistória.

Chamam a atenção indícios pertinentes esteados em referências articuladas pelo enunciante da resenha. Em primeiro lugar, frisamos o aspecto interdiscursivo, com o traspassamento do discurso histórico - [...] além de conter muitos fatos e personagens bistóricos, como "Napoleão Bonaparte na sua fuga da ilha de Elba para recuperar o trono perdido". É algo que dá um tom maior de veracidade ao romance. Fica sugerido, assim, que o efeito de realidade num romance é uma qualidade apreciável. Surge, ademais, o indício de experiência literária do enunciante da resenha - Este livro, "assim como vários outros de Alexandre Dumas", consegue prender a atenção do leitor e viciá-lo na bistória.

Possenti (2009b, p.109) elenca certos aspectos indiciários de autoria como, nos termos do próprio autor, a "relação com elementos de cultura e com outros discursos", e "densidade". Como verificamos em nossa análise, a resenha sobre $\mathrm{O}$ Conde de Monte Cristo é um texto denso o bastante e reúne tais relações interdiscursivas.

O primeiro parágrafo, relativamente ao conjunto, funciona como uma síntese descritiva (lide), que "empurra" o leitor para o enredamento.

Resenha 2 - Até onde o amor pode levar (Resenha do livro Os sofrimentos do Jovem Werther) [GOETHE, Johann Wolfgang Von. Os Sofrimentos do Jovem Werther. Martin Claret. São Paulo, 2002]

O romance Os Sofrimentos do Jovem Werther (Martin Claret, Coleção A Obra-Prima de Cada Autor, 2002), do autor alemão Johann Wolfgang Von Goethe, é uma obra turbulenta e que leva o leitor à reflexão (1). Goethe, destacado pela sua vitalidade, utilizou acontecimentos vivenciados por ele próprio em seu tempo para produzir a obra (2). O jovem Werther, protagonista da história, vive um amor proibido, pois Charlotte (Lotte), a sua amada, é comprometida. Mesmo não podendo tê-la, Werther não se afasta, o que faz com que seu sofrimento aumente. Diante disso, ele toma uma decisão que mexe com a vida de muitas pessoas. O romance compõe-se de acontecimentos que mostram uma sociedade que considerava o sofrimento por uma paixão proibida algo mais insensato do que ainda se considera hoje em dia (3). Os Sofrimentos do Jovem Werther é um romance que prende o leitor, despertando o interesse e a curiosidade. O autor consegue levar quem lê a vivenciar um pouco do sofrimento que o jovem Werther sentira (4). 
Esse texto distingue-se do primeiro porque opera mais sumariamente com os elementos comuns à resenha. Vai rapidamente de uma apresentação ao resumo e, no mesmo ritmo, para a avalição. A resenha é, então, mais curta. Sobre a extensão temos duas hipóteses que não necessariamente se excluem. Em primeiro lugar, talvez seja a tentativa natural de reproduzir uma extensão textual da qual se obteve consciência por meio da observação de um tipo mais curto do gênero que circula no meio social. Em segundo lugar, muitos alunos, quando solicitados a produzir textos, tendem à concisão. Isso se deve a várias razões - entre elas, pode ser ainda a pouca familiaridade com a escrita, com o gênero, com o assunto, tempo curto para escrever, insegurança, medo de se expor etc.

De uma forma ou de outra, a curta extensão da resenha não vai a contrapelo da singularidade, até porque, como já comentamos, o gênero favorece a autoria. $\mathrm{O}$ segundo texto parece mesmo mais acanhado em relação ao primeiro. Ainda assim, não é preciso esforço para visualizar indícios muito pertinentes de um sujeito se movimentando entre as fronteiras do gênero. Como a resenha é composta por um único parágrafo, optamos por dividi-lo em segmentos.

Comecemos pela variação na maneira de avaliar:

De (1): O romance Os Sofrimentos do Jovem Werther [...] é uma "obra turbulenta e que leva o leitor à reflexão".

De (2): [...] Goethe, "destacado pela sua vitalidade" (Não ficou muito claro o que se quis dizer com "vitalidade", mas a tomada de posição procede).

De (4): Os Sofrimentos do Jovem Werther é um romance "que prende o leitor, despertando o interesse e a curiosidade". O autor consegue "levar quem lê a vivenciar um pouco do sofrimento que o jovem Werther sentira".

Observemos também os dados sobre o contexto em que o livro resenhado foi escrito. São articulações que nos remetem mais uma vez a Possenti (2009b) e a sua reflexão sobre o laço estreito entre autoria e as alusões aos elementos da cultura. Vejamos os excertos:

Goethe, destacado pela sua vitalidade, utilizou acontecimentos vivenciados por ele próprio em seu tempo para produzir a obra (2).

O romance compõe-se de acontecimentos "que mostram uma sociedade que considerava o sofrimento por uma paixão proibida algo mais insensato do que ainda se considera boje em dia" (3).

O segmento (2) reporta a um enunciante que talvez não se coloque apenas para informar, mas também para mostrar que houve empenho em conhecer o autor do livro resenhado, apesar de não constarem informações comumente recorrentes 
sobre obras, tais como o fato de dizer respeito a comunidades do século XVIII e de tratar-se de um texto do romantismo alemão que fez muito sucesso à época.

O segmento (3), por sua vez, empreende, com base no romance, uma reflexão sobre a paixão na sociedade de outrora e na contemporaneidade. $\mathrm{O}$ enunciante vincula a sua reflexão uma breve apreciação acerca do passado e do presente. Nos dois momentos, segundo o seu texto, há relações afetivas que eram e permanecem malvistas - "que mostram uma sociedade que considerava o sofrimento por uma paixão proibida algo mais insensato do que ainda se considera boje em dia" (3).

As observações para os segmentos (2) e (3) coincidem, de alguma forma, com duas tarefas, elencadas por Bakhtin diante da apreensão de uma obra:

A primeira tarefa é compreender uma obra da mesma maneira como a compreendeu o próprio autor sem sair dos limites da compreensão dele. A solução dessa tarefa é muito difícil e costuma exigir mobilização de grande material.

A segunda tarefa é utilizar a sua distância temporal e cultural. Inclusão no nosso (alheio para o autor) contexto. (BAKHTIN, 1979/2010, p. 381)

Em (2) e (3), o trabalho do enunciante certamente não está sustentado em uma grande variedade de material como a de que fala Bakhtin; está distante disso, e um grande aprofundamento não é necessariamente uma esperança pedagógica. Entretanto, em (2) e (3) sucedem algum exame e preocupação sobre um passado determinado: o período em que viveu o autor da obra resenhada. Tão importante quanto isso é o tratamento apreciativo que traz a obra para o contexto do enunciante. Nesse ponto, sim, uma das tarefas, a segunda, é cumprida integralmente.

O planejamento, orientado pela perspectiva sociointeracionista, tende a promover o diálogo com esses aspectos da cultura e da história e, ao mesmo tempo, respeita o ponto de vista do aluno, determinado por seu próprio contexto, para, assim, produzir suas réplicas a partir do que foi apreendido da palavra do outro.

Entrevemos, então, em (2) e (3) indícios de autoria. O enunciante compara, avalia, além de estabelecer relações com elementos da história e da biografia do autor resenhado. Dissemos anteriormente que, comparado ao primeiro texto, o segundo parece mais tímido. Apesar disso, o sujeito, em boa medida, projeta-se e atende o chamado à autoria que o gênero em questão implica.

A próxima resenha é certamente a que incorpora mais traços autorais. Comparado aos dois textos anteriores, em tudo o enunciante estampa mais ênfase, variação e performance; isso é visto nas relações que estabelece, nos julgamentos, nas tomadas de posição, na variedade vocabular e até no que é atípico em resenhas mais uniformizadas. Vejamos: 
Resenha 3 - G.K. Chesterton: Tremendas Trivialidades [CHESTERTON, G. K. Tremendas trivialidades. Ecclesiae. Campinas, 2012].

Grandes sacadas têm o poder de, frequentemente, mudar o rumo de nossas opiniões. Mas, depois que passei a ler Chesterton, descobri que, na realidade, é a atividade de enxergar as pequenas coisas que sempre estiveram presentes em nosso cotidiano que faz com que, eventual e consequentemente, passemos a encarar também a vida de uma forma renovada.

Tremendas Trivialidades, da editora Ecclesiae, de São Paulo, reúne 39 crônicas jornalísticas de Chesterton, publicadas originalmente em jornais londrinos no começo do século XX. Todas as crônicas, por mais diversificadas que sejam, nos fazem refletir sobre, pelo menos, uma verdade: a de que não existem coisas desinteressantes. Você poderia discordar e dizer que o simples fato de chover de vez em quando é algo tão ordinário que nem chega a ser digno de sua atenção, mas este é o ponto: o problema não está exatamente na chuva. Neste caso, basta reparar em como, milênios atrás, os gregos a consideravam uma dádiva de Zeus, o senhor do céu. Se isso não é uma forma de apreciar as coisas, eu não sei o que poderia ser.

Já no começo do livro, Paulo Briguet, jornalista e cronista em Londrina, nos fala sobre a "impossibilidade de prefaciar Chesterton" alegando que "o prefácio de um autor alheio servirá apenas para aumentar a distância entre o leitor e o tesouro literário que se acha nas próximas páginas". E, de fato, o prazer de ler Chesterton não é algo que deva ser protelado.

Sua peculiar habilidade de expressão unida ao seu senso de humor inteligente the rendeu o título de "príncipe do paradoxo", o que pode ser comprovado mesmo na leitura da menor de suas crônicas. Algumas publicações como O Taxista Extraordinário, As Vantagens de Ter uma Perna, Sobre Ficar na Cama, O País de Pernas para o Ar, A Avó do Dragão, O Barbeiro Ortodoxo e a própria Tremendas Trivialidades me encantaram tanto que, antes que eu me desse conta, já as tinha relido diversas vezes e para vários de meus amigos. Os escritos de Chesterton são apenas mais uma prova de que, como ele mesmo diz, "o mundo nunca sofrerá com a falta de maravilhas (...)"

\section{A seguir, o primeiro parágrafo destacado para as observações:}

Grandes sacadas têm o poder de, frequentemente, mudar o rumo de nossas opiniões. Mas, depois que passei a ler Chesterton, descobri que, na realidade, é a atividade de enxergar as pequenas coisas que sempre estiveram presentes em nosso cotidiano que faz com que, eventual e consequentemente, passemos a encarar também a vida de uma forma renovada.

O enunciante defende o livro argumentando que após a leitura houve uma mudança da sua percepção das coisas e, consequentemente, da vida. Notamos a utilização do operador argumentativo mas para realizar a transição entre uma visão mais limitada do mundo e a nova percepção adquirida com a leitura do livro de Chesterton - Mas, depois que passei a ler Chesterton, descobri [...]. Ao longo do texto, a defesa de Tremendas Trivialidades mantém-se sempre desse modo apaixonado. A tomada de posição de maneira intensa mostra que a resenhista decide correr riscos e se projetar discursivamente. Contribui para isso o tom de testemunho, perceptível já no primeiro parágrafo, ao assumir uma mudança pessoal. $\mathrm{O}$ aspecto é reforçado 
pela utilização da primeira pessoa do singular - Mas, depois que "passei" a ler Chesterton, "descobri" [...]. Assim como na primeira resenha analisada, a incidência da primeira pessoa no texto agora observado aponta para um lugar discursivo escolar. É um comportamento linguístico que mais ou menos baliza a inscrição em um grupo social. Como dissemos anteriormente, é atípico o seu uso em resenhas cuja esfera de produção suscita uma maior uniformização do gênero. As mesmas considerações são válidas para a utilização do pronome possessivo de primeira pessoa plural "nosso" cotidiano. Inclusive ao longo de todo o texto há uma variação da pessoa do discurso.

Também são importantes algumas expressões de modalidade que ocorrem na apresentação da resenha - [...] descobri que, "na realidade" [...] - [...] "sempre" estiveram presentes $[\ldots]-[\ldots]$ "que faz com que" [...] passemos a encarar [...]. As expressões são incisivas, indicando um sujeito que força sua presença no texto sem receio de posicionar-se.

A variação vocabular, por seu turno, ao menos no primeiro parágrafo, cria um tom existencial e incorpora elementos indicativos de um sujeito que faz reflexões - Grandes sacadas - enxergar as pequenas coisas - cotidiano - encarar também a vida de uma forma renovada.

Vejamos o segundo parágrafo:

Tremendas Trivialidades, da editora Ecclesiae, de São Paulo, reúne 39 crônicas jornalísticas de Chesterton, publicadas originalmente em jornais londrinos no começo do século XX. Todas as crônicas, por mais diversificadas que sejam, nos fazem refletir sobre, pelo menos, uma verdade: a de que não existem coisas desinteressantes. Você poderia discordar e dizer que o simples fato de chover de vez em quando é algo tão ordinário que nem chega a ser digno de sua atenção, mas este é o ponto: o problema não está exatamente na chuva. Neste caso, basta reparar em como, milênios atrás, os gregos a consideravam uma dádiva de Zeus, o senhor do céu. Se isso não é uma forma de apreciar as coisas, eu não sei o que poderia ser.

As primeiras sequências fazem uma pequena síntese do livro, dizendo do que se trata e contextualizando a obra. $\mathrm{O}$ aspecto argumentativo já se mostra logo em seguida. Tanto nesse parágrafo, como no restante do texto, a argumentatividade é bem aparente, inclusive em relação aos outros textos aqui analisados. Isso não quer dizer que as outras duas resenhas não tenham a mesma caraterística, até porque o gênero demanda argumentatividade, dada a necessidade de avaliar positiva ou negativamente uma obra. Mas nesse sentido, o texto sobre Tremendas Trivialidades é evidentemente marcante. $\mathrm{O}$ vocabulário é um fator que robustece os posicionamentos do enunciante. Assim como no parágrafo anterior, a variação vocabular envolve sempre um grau de modalidade vigoroso. Vejamos alguns exemplos: "Todas as crônicas" [...] nos fazem refletir sobre, pelo menos, "uma verdade": a de que "não existem coisas desinteressantes". 
O vocabulário empregado contribui para a força ilocutória dos enunciados, que consistem frequentemente em asseverações. É perceptível a tentativa de fechamento para sentidos divergentes que possam ser produzidos acerca do livro resenhado. Em nossa concepção são traços autorais à medida que remetem a um sujeito que consistentemente tenta expor o seu envolvimento com a obra.

Um movimento que chama a atenção é o uso da segunda ${ }^{6}$ pessoa do singular você. Em outras resenhas escolares, ao menos em nossa experiência, tem sido um traço pouquíssimo frequente; acreditamos que em resenhas jornalísticas menos ainda. Os gêneros publicitários, por outro lado, utilizam-na frequentemente com o mesmo objetivo da resenhista de Tremendas Trivialidades: convencer o interlocutor. A ocorrência de você, tal como a da primeira pessoa também empregada nessa resenha, gera um efeito de aproximação com o leitor. Com isso, o sujeito produz um tipo de texto intimista - Você poderia discordar e dizer que o simples fato de chover de vez em quando é algo tão ordinário que nem chega a ser digno de sua atenção mas este é o ponto [...]. Aqui, a resenhista incorpora a voz do interlocutor antecipando um possível posicionamento seu - Você poderia discordar e dizer que [...] - para logo em seguida empregar o operador argumentativo mas, que introduz um argumento contrário - mas este é o ponto: o problema não está exatamente na chuva [...]. Em complemento, produz uma parada com dois pontos para um alerta. Essa tática estilística ocorre também três linhas antes: nos fazem refletir sobre [...] uma verdade: a de que não existem [...], embora aqui ainda houvesse uma possibilidade de economia (conforme destacado por Bakhtin (1940-1945/2013)): uma verdade: não existem coisas desinteressantes.

Em suas reflexões sobre elementos sintáticos, Bakhtin/Voloshinov (1929/1986, p.141) considera um tipo clássico de parágrafo o que prevê e incorpora possíveis objeções do interlocutor. Como vimos, o parágrafo analisado denota o interesse pela reação do outro. Ainda segundo Bakhtin, a orientação para o outro dá mostras de uma melhor organização discursiva em relação ao parágrafo. Do contrário, segundo o autor (1929/1986, p.141): "Quanto mais fraco o ajustamento ao ouvinte e a consideração das suas reações, menos organizado, no que diz respeito aos parágrafos, será o discurso". A publicação em revista dá a oportunidade de interação com um interlocutor real. Provavelmente, esse é um dos motivos da aparição de um você genérico no texto, com a antecipação de suas reações. É menos provável um você referenciando um professor, caso este último seja o único interlocutor do aluno. Seria igualmente incomum a antecipação das reações do professor, por parte do

\footnotetext{
6 Estamos tratando o pronome você como segunda pessoa do singular porque efetivamente designa
} um interlocutor e não uma terceira pessoa (não pessoa) de quem se fala. 
resenhista, se a interlocução estivesse limitada somente aos dois e a finalidade única da produção do texto fosse a sua correção.

A continuação da argumentação agencia, de modo inteligente, um discurso histórico - Neste caso, basta reparar em como, milênios atrás, os gregos a consideravam uma dádiva de Zeus, o senhor do céu. Em seguida, complementa-se com uma condicional, em que podem ser vistos, também, alto grau de modalidade e utilização da primeira pessoa do singular - "Se" isso "não é" [...] "eu nãa sei" o que poderia ser. Podemos ver aqui, também, de forma atenuada, o que Authier-Revuz tem tratado como metaenunciação - o retorno às próprias palavras, pesando-as. Cremos que todos os elementos mencionados segunda e primeira pessoa do singular; uso de operador argumentativo; relação com elementos da cultura e da história; condicional; alto grau de modalidade; metaenuciação, previsão de reações - são indícios de autoria significativos.

Vamos ao terceiro parágrafo:

Já no começo do livro, Paulo Briguet, jornalista e cronista em Londrina, nos fala sobre a "impossibilidade de prefaciar Chesterton" alegando que "o prefácio de um autor alheio servirá apenas para aumentar a distância entre o leitor e o tesouro literário que se acha nas próximas páginas". E, de fato, o prazer de ler Chesterton não é algo que deva ser protelado.

Vemos um processo de intertextualidade que se constrói por meio de duas citações diretas do prefácio do livro resenhado. A resenhista empreende uma espécie de apelo à autoridade, no caso, ao autor do prefácio. Em sentido geral, o recurso da referência à autoridade serve para reforçar a argumentação e os posicionamentos. No texto em questão, o recurso é usado em defesa do livro de Chesterton e ao mesmo tempo abona a própria resenha, pois dá voz a um especialista que também enaltece o autor britânico.

Como em todo o texto, as variações de expressão e de vocabulário permanecem fortalecendo a argumentação. Para a introdução da segunda citação do autor, o verbo dicendi alegar é utilizado - Paulo Briguet [...] nos fala sobre a "impossibilidade de prefaciar Chesterton" "alegando" que "o prefácio [...]'". O último enunciado do parágrafo também condiz com as pretensões argumentativas do texto: E, "de fato", "o prazer de ler" Chesterton não é algo que "deva ser protelado". Assim como no bloco analisado anteriormente, a força ilocutória é de asseveração. Da mesma forma, o resenhista continua tentando impedir a produção de sentidos discordantes sobre o livro de Chesterton.

Por fim, vamos observar o quarto e último parágrafo.

Sua peculiar habilidade de expressão unida ao seu senso de humor inteligente lhe rendeu o título de "príncipe do paradoxo", o que pode ser comprovado mesmo na leitura da menor de 
suas crônicas. Algumas publicações como O Taxista Extraordinário, As Vantagens de Ter uma Perna, Sobre Ficar na Cama, O País de Pernas para o Ar, A Avó do Dragão, O Barbeiro Ortodoxo e a própria Tremendas Trivialidades me encantaram tanto que, antes que eu me desse conta, já as tinha relido diversas vezes e para vários de meus amigos. Os escritos de Chesterton são apenas mais uma prova de que, como ele mesmo diz, "o mundo nunca sofrerá com a falta de maravilhas (...)"

Ao longo do texto, o resenhista apela algumas vezes ao já-dito, como quando alude ao autor do prefácio do livro ou quando traz uma informação sobre os antigos gregos. O resenhista inicia o parágrafo em foco exaltando o autor e outra vez reporta o já-dito para tornar conhecido o epíteto de Chesterton - Sua peculiar babilidade de expressão [...] "The rendeu o título de "príncipe do paradoxo". As operações intertextuais da resenha insinuam que há um sujeito preocupado e comprometido com a inserção de outras vozes de modo que a defesa do objeto resenhado seja consistente. Bakhtin, em "Os gêneros do discurso" (1979/2010, p. 272, grifo do autor), diz que

[...] cedo ou tarde o que foi ouvido e ativamente entendido responde nos discursos subsequentes ou no comportamento do ouvinte. Os gêneros da complexa comunicação cultural, na maioria dos casos, foram concebidos precisamente para essa compreensão ativamente responsiva de efeito retardado. Tudo o que aqui dissemos refere-se igualmente, mutatis mutandis, ao discurso escrito e ao lido.

Assim, as operações intertextuais constituem uma atualização de discursos, conteúdos e formas, que se entrelaçam no texto enquanto acontecimento também tomado de memória. Nesse contexto, a ideia de autor, mesmo rudimentar, se faz presente porque a atualização, o acontecimento discursivo, denota um novo arranjo concebido por um sujeito e suas possibilidades.

No parágrafo analisado, a primeira pessoa do singular volta a aparecer. Junto com ela, a alusão aos amigos provoca um tipo de abertura à intimidade que mais uma vez aponta para um lugar discursivo escolar - [...] e a própria Tremendas Trivialidades "me" encantaram tanto que, antes que "eu" me desse conta, já as tinha "relido" diversas vezes e "para vários de meus amigos".

Focalizamos, finalmente, a relação entre a variação vocabular e o grau de modalidade das avaliações. O acento laudatório de todo o texto conserva-se até o fim - "peculiar babilidade" de expressão; senso de bumor "inteligente"; [...] o que pode ser "comprovado" "mesmo" na leitura da "menor" de suas crônicas; [...] me "encantaram" "tanto" que, "antes que eu me desse conta", já as tinba relido "diversas" "vezes" e para "vários" de meus amigos; Os escritos de Chesterton são apenas "mais uma prova" de que, como ele mesmo diz [...] 


\section{DISCUSSÃO}

O gênero resenha vem se mostrando bastante atrativo para os alunos. Nesse sentido, tem-se trabalhado para o despertar da curiosidade em relação a produtos culturais que escapem da condição best seller/ blockbuster. Nas aulas de leitura, o aspecto crítico é um ponto importante porque traz à baila, junto aos alunos, o debate sobre os elementos discursivos e extralinguísticos implicados pelo gênero. Emergem questões como: o que o resenhista diz sobre o que está sendo resenhado procede? A resenha pode ser uma forma de publicidade? Por que livros, filmes, discos mais antigos quase não são resenhados? Por que um mesmo veículo não mostra duas opiniões diferentes, isto é, duas resenhas, sobre um mesmo tema? São questões essenciais porque também incitam a reflexão sobre a argumentação e os gêneros em que essa tipologia predomina. Não são poucos os alunos que chegam ao terceiro ano pensando que texto argumentativo corresponde somente à redação escolar tradicional.

O outro aspecto instigante do estudo da resenha é sua abertura para a intertextualidade e para dialogicidade no que diz respeito ao que os alunos estão lendo, ouvindo ou assistindo. Eles são estimulados a produzir resenhas sobre os livros, filmes, ou álbuns musicais de sua preferência. Isso lhes dá uma oportunidade de expressar opiniões e de compartilhar interesses sobre o que de fato vivenciam por iniciativa própria.

Dado importante é que nem sempre é possível comportar toda a produção textual discente em um contexto de interação cem por cento concreto, como no caso de revistas, jornais e blogs escolares. Importa, então, no trabalho em sala de aula, criar um perfil aproximado de leitor, ainda que esse leitor não exista efetivamente. Endossamos a opinião de Oliveira, quando reflete sobre o assunto:

Produzir um texto que satisfaça as expectativas do leitor é impossível se não soubermos quem é o leitor. Isso não é óbvio? E. Então por que muitos professores ainda não estabelecem um leitor, mesmo fictício, para a produção textual de seus alunos? Saber para quem se escreve não significa conhecer o leitor pessoalmente nem saber exatamente o perfil desse leitor. Todavia, precisamos ter uma ideia do perfil desse leitor, mesmo que seja um perfil genérico. (OLIVEIRA, 2010, p. 140).

Além de criar um perfil de leitor, o professor não deve se furtar a simular circunstâncias aproximadas das situações reais de interação. Nossa experiência indica que, assim, o resultado também é positivo e muito diferente do obtido pelas práticas apartadas de procedimentos didáticos mais dialógicos. 
A percepção das condições de produção e observação/aceitação de que, como diz Barthes (1984/2004), o autor se perde no tempo quando a escritura começa a produzir seus efeitos, é um alerta para a compreensão de que, como prática de subjetivação bem-sucedida, o movimento autoral produz a "morte" do autor no sentido, apenas aparentemente contraditório, de ser a própria produção que lhe permite deixar uma marca, produzir algo que pode ter efeito muito tempo depois da morte física, para além de supostas intenções - não mais, por princípio, disponíveis. O papel do autor, em seu crescente movimento, está justamente configurado em seu "representante": a obra, a demonstração de um acontecimento que fornece traços de tempo, espaço e memória (saberes) e relações humanas. Trata-se de uma imagem de autoria amarrada a uma "filiação" de caráter histórico - portanto, discursiva.

\section{CONSIDERAÇÕES FINAIS}

O tratamento dado à linguagem a partir de um entendimento dialógico inevitavelmente conduz professor e aluno a um estado de nivelamento de suas posições; não são os papéis, as opiniões ou valores que coincidem, mas, sim, o poder dizer de cada parte. O professor deve permitir isso. Se o consenso absoluto é inexequível, a dialogização da vida não deveria ser. Faraco (2009, p.75-76) rememora a utopia bakthiniana a respeito de um mundo menos monológico. Dar voz ao outro, para que concorde, para que discorde, como desejou o autor russo, é mais que nobre. É ético. Há tendências autoritárias latentes (ou evidentes) em todas as esferas sociais, intencionando impugnar o diálogo vital. Por isso, esse diálogo é o que se deve privilegiar no pequeno canto do mundo chamado sala de aula. São fundamentais, então, o respeito aos alunos, a seu contexto e o favorecimento de sua produção autoral, servindo-se tanto de tecnologia mais antiga - o papel e a impressão - quanto da mais recente, acessível e utilizada pelos jovens - a internet. Da parte docente, não é difícil incorrer em vícios atávicos, mas a bússola dialógica pode apontar outra vez o caminho. Daqui podemos retornar à epígrafe deste trabalho, e continuar com Wall (2006, p. 316): "No final, acabamos vendo os benefícios de nos comportarmos como se realmente acreditássemos que pensamos melhor em conjunto do que quando tentamos pensar sozinhos". 


\section{REFERÊNCIAS BIBLIOGRÁFICAS}

AUTHIER-REVUZ, J. (2008). O estrato meta-enunciativo, lugar de inscrição do sujeito em seu dizer: implicações teóricas e descritivas de uma abordagem literal. O exemplo das modalidades irrealizantes do dizer. Matraga, Rio de Janeiro, v. 15, n. 22, pp. $33-$ 63.

BAKHTIN, M./VOLOSHINOV, V. N. (1929). Marxismo e filosofia da linguagem. Tradução de Michel Lahud e Yara Frateschi Vieira. São Paulo: Hucitec, 1986.

BAKHTIN, M. Estética da criação verbal (1979). Tradução de Paulo Bezerra. 5. ed. São Paulo: Martins Fontes, 2010.

BAKHTIN, M. (1940-1945). Questões de estilística no ensino da língua. In: Bakhtin, M. Questões de estilística no ensino da língua. Tradução de Sheila Grillo e Ekaterina Vólkova Américo. São Paulo: Editora 34, 2013. pp. 23-43.

BARTHES, R. (1984). A morte do autor. In: Barthes, R. O rumor da língua. Tradução de Mário Laranjeira. 2. ed. São Paulo: Martins Fontes, 2004. pp. 57-64.

CLARK, K.; HOLQUIST, M. (1984). Mikbail Bakbtin. Tradução de J. Guinsburg. São Paulo: Perspectiva, 1998.

DERRIDA, J. (1990). Limited inc. Tradução de Constança Marcondes Cesar. Campinas: Papirus, 1991.

FARACO, C. A. (2009). Linguagem e diálogo: as ideias linguísticas do Círculo de Bakhtin. São Paulo: Parábola Editorial.

FOUCAULT, M. (1969). O que é um autor? 3. ed. Tradução de Antônio Fernando Cascais e Eduardo Cordeiro. Vega: Passagens, 1997.

FURLANETTO, M. M. (2014). Ler, escrever, "pontuar": a construção da autoria. Leia Escola, v. 14, n. 1, pp. 61-73.

FURLANETTO, M. M. (2015). Formação discursiva, autoria, filiações e metáfora. Fórum Linguístico, Florianópolis, v. 12, n. 1, pp. 595-610, jan./mar.. Disponível em: <https:// periodicos.ufsc.br/index.php/forum/article/view/1984-8412.2015v12n1p595>. Acesso em: 01 out. 2015.

OLIVEIRA, L. A. (2010). Coisas que todo professor de português precisa saber: a teoria na prática. São Paulo: Parábola Editorial.

POSSENTI, S. (2009a). Enunciação, autoria e estilo. In: Possenti, S. Questões para analistas do discurso. São Paulo: Parábola, pp. 91-101.

POSSENTI, S. (2009b). Indícios de autoria. In: Possenti, S. Questões para analistas do discurso. São Paulo: Parábola, pp. 103-117.

POSSENTI, S. (2013). Notas sobre a questão da autoria. Matraga, Rio de Janeiro, v. 20, n. 32, pp. 239-250. Disponível em: < http://www.pgletras.uerj.br/matraga/matraga32/ arqs/matraga32a13.pdf $>$. Acesso em: 01 set. 2015. 
WALL, A. Por uma estética da recepção bakhtiniana ou $\mathrm{O}$ valor da mudança de expectativas. In: Faraco, C. A.; Tezza, C.; Castro, G. de (Org.) (2006). Vinte ensaios sobre Mikbail Bakbtin. Petrópolis: Vozes, pp. 305-318.

Recebido: 10/10/2015

Aceito: 04/08/2016 


\section{ERRATA}

\section{Artigo: INDÍCIOS DE AUTORIA NA PRODUÇÃO DE RESENHAS DE ESTUDANTES}

DE ENSINO MÉDIO

Publicação: Trab. linguist. apl. v55n3a10, 777-804, Campinas set./dez. 2016

DOI: bttp://dx.doi.org/10.1590/010318134863171881

Pág 777 - Trocar a cidade da instituição do autor na nota de rodapé

Onde se lia:

** Instituto Federal de Educação, Ciência e Tecnologia de Sergipe, São Cristóvão (SE), Brasil. vinimacedo@uol.com.br

Leia-se:

** Instituto Federal de Educação, Ciência e Tecnologia de Sergipe, Aracajú (SE), Brasil. vinimacedo@uol.com.br 